\title{
TRADUÇÃO INTERMODAL, INTERSEMIÓTICA E INTERLINGUÍSTICA DE TEXTOS ESCRITOS EM PORTUGUÊS PARA A LIBRAS ORAL
}

\author{
Rimar Ramalho Segala* \\ Universidade Federal de São Carlos
}

Ronice Müller de Quadros**

Universidade Federal de Santa Catarina

\begin{abstract}
Resumo: Neste artigo apresentamos alguns tipos de tradução envolvidos na tradução de textos em português para a língua brasileira de sinais ( $\mathrm{Li}-$ bras). Discutimos esses diferentes tipos e destacamos a tradução intermodal, específica das traduções que envolvem uma língua de sinais. A tradução intermodal trata de aspectos visuais e operacionais implicados na tradução para Libras em forma de vídeo e aspectos linguísticos essencialmente visuais-espaciais que envolvem o uso do espaço em línguas de modalidade visual-espacial, ou seja, línguas de sinais. Neste artigo, apresentamos uma análise das implicações da modalidade a partir de exemplos de tradução realizados no contexto do Curso de Letras Libras da Universidade Federal de Santa Catarina (UFSC).
\end{abstract}

\footnotetext{
* Rimar Ramalho Segala é Mestre (2010) em Estudos da Tradução pela Universidade Federal de Santa Catarina. Atualmente é Professor Assistente na Universidade Federal de São Carlos. São Carlos, São Paulo, Brasil. E-mail: rimar@ ufscar.br

** Ronice Müller de Quadros é Mestre (1995) e Doutora (1999) em Linguística pela Pontifícia Universidade Católica do Rio Grande do Sul. Pós-Doutora pela University of Connecticut e Gallaudet University, Estados Unidos (2009-2010) e Harvard University (2015-2016). Atualmente é Professora Associada na Universidade Federal de Santa Catarina, Florianópolis, Santa Catarina, Brasil. E-mail: ronice.quadros@ufsc.br
} 
Palavras-chave: Libras. Tradução intermodal. Tradução Interlinguística. Tradução Intersemiótica.

\title{
INTERMODAL, INTERSEMIOTIC, AND INTERLINGUISTIC TRANSLATION OF WRITTEN TEXTS IN PORTUGUESE TO ORAL LIBRAS
}

\begin{abstract}
In this paper, we present some types of translation involved in the translation from written Portuguese to Brazilian Sign Language (Libras). We discuss these different types and we focus in the intermodal translation, that it is specific of language pairs in which the modalities are different. The intermodal translation brings visual and operational aspects implied in the translation to Libras in video format and visuo-spatial linguistics aspects related to the use of the space in languages in which the modality is visuo-spatial, such as sign languages. In this paper, we show an analysis of the modalities consequences with translated examples done in the context of Libras Program, Letras Libras, from the Universidade Federal de Santa Catarina (UFSC).
\end{abstract}

Keywords: Libras. Intermodal translation. Interlinguistics translation. Intersemiotic translation.

\section{Introdução}

\section{Tradução de Língua de Sinais}

Nos últimos 20 anos, os estudos da tradução de línguas de sinais começam a se configurar no Brasil (SANTOS, 2013). Por vários anos, as produções sobre a tradução e/ou a interpretação da Libras e Língua Portuguesa estiveram presentes nos campos educacionais e linguísticos, com enfoque mais aplicado, especialmente voltados para o estudo das práticas de tradução e/ou interpretação em contextos educacionais. Nos últimos anos, no entanto, percebemos uma mudança, pois as produções envolvendo pesquisas com a tradução e interpretação incluindo a Libras no par linguístico Libras e Língua Portuguesa estão mais situadas no campo dos Estudos da 
Tradução (SANTOS, 2013; QUADROS, 2015). Mais especificamente, a área da tradução de língua de sinais no Brasil se estabelece a partir da criação dos Cursos de Letras Libras, em 2006 e, como consequência, ganha espaço no Programa de Pós-Graduação em Estudos da Tradução, na UFSC. No Curso de Letras Libras, todos os materiais foram traduzidos para a Libras, envolvendo equipes de tradução com a presença de tradutores surdos e intérpretes de língua de sinais. Os tradutores sentiram a necessidade de estabelecer estratégias para a realização das traduções do Português escrito para a Libras. Paralelamente a esse processo empírico, avançou-se nas pesquisas que consolidaram o campo da tradução de língua de sinais e português, nos Estudos da Tradução (SEGALA, 2010; SOUZA, 2010; BARAZZUTTI, 2011; PIMENTA, 2012; FELÍCIO, 2013; SANTOS, 2013; LUCHI, 2013; BARBOSA, 2014, entre outros).

Há uma tradição nos estudos de línguas de sinais de identificar o que há em comum com os estudos das línguas faladas, mas, ao mesmo tempo, a necessidade de identificar suas especificidades e explicá-las no contexto dos estudos linguísticos (PADDEN, 1988; QUADROS, 2006). As pesquisas indicam vários aspectos linguísticos comuns entre as línguas de sinais e as línguas faladas. Por exemplo, segundo Quadros e Karnopp (2004), a Libras apresenta unidades mínimas que constituem os fonemas dessa língua: um conjunto de configurações de mão, um conjunto de locações onde os sinais são produzidos no espaço de sinalização, um conjunto de movimentos aplicados aos sinais, um conjunto de orientações de mão, que combinados formam os sinais. Assim, como em vários outros estudos com outras línguas de sinais, foi delineada a fonologia das línguas de sinais (por exemplo, STOKOE, 1960 para a língua de sinais americana). Mesmo assim, todos reconhecem que o fato das línguas de sinais usarem um canal visual-espacial, com a produção de palavras com o uso das mãos, tem efeitos na percepção e na própria produção dessas palavras que são processados diferentemente das palavras produzidas com línguas faladas. Por exemplo, as crianças apresentam mais facilidade em perceber as 
palavras visualmente e reproduzi-las por que elas veem os sinais serem articulados fisicamente, diferentemente das crianças que ouvem os sons, mas não conseguem visualizar a sua articulação (MEIER, 1980). Isso aconteceu em todos os demais níveis de análise da linguística (ver, por exemplo, PFAU; STEINBACH; WOLL, 2012). Nos últimos anos, estamos vivenciando um momento muito rico no campo dos estudos das línguas de sinais, pois as pesquisas estão investigando o que há de diferente nas línguas de sinais que poderá contribuir para a linguística de modo geral (QUADROS, 2014). Um dos aspectos levantados nos estudos das línguas de sinais considerado peculiar a estas línguas é a questão dos efeitos de modalidade. Quadros (2006) apresenta vários autores que discutiram a questão da modalidade visual-espacial das línguas de sinais. Entre eles, Padden (1988), Bahan, (1996), Lillo-Martin (2002) são exemplos de autores que discutiram a questão do uso do espaço e suas implicações nas línguas de sinais. Os autores nomearam os usos do espaço como sintaxe espacial, gramática espacial, sistema nominal espacial e assim por diante. De modo geral, os autores chegam a mesma conclusão:

Por um lado, existe uma preocupação em relação aos efeitos das diferenças na modalidade fazendo com que os estudos das línguas de sinais sejam extremamente relevantes. Por outro lado, as similaridades encontradas entre as línguas faladas e as línguas sinalizadas parecem indicar a existência de propriedades do sistema linguístico que transcendem a modalidade das línguas. Nesse sentido, o estudo das línguas de sinais tem apresentado elementos significativos para a confirmação dos princípios que regem as línguas humanas. (QUADROS, 2006, p.176).

Em relação aos estudos da tradução e interpretação de línguas de sinais, também estamos iniciando as investigações buscando paralelos com a tradução e interpretação de outras línguas e estamos analisando as possíveis especificidades que se aplicam no caso das 
línguas de sinais. Da mesma forma que nos estudos linguísticos, nós estaremos discutindo a tradução no par linguístico que inclui uma língua de sinais, analisando os diferentes tipos de tradução com enfoque na tradução intermodal que permeia a tradução interlingual e a tradução intersemiótica nesse contexto, ou seja, estaremos analisando as questões específicas decorrentes da presença de uma língua visual-espacial.

Vamos retomar estes diferentes tipos de tradução que foram discutidos por Jakobson (1959) para compreender como a tradução intermodal proposta neste artigo contribui para a compreensão e explicação das especificidades da tradução envolvendo uma língua de sinais.

Jakobson (1959) distingue três tipos de tradução:

1. Tradução intralingual ou reformulação, a interpretação da língua para mesma língua (por exemplo, o texto de adulto para texto infantil).

2. Tradução interlingual ou tradução propriamente dita, que é definida como a interpretação de uma língua para outra; ou seja, uma interpretação de signos verbais de uma língua para outra língua.

3. Tradução intersemiótica ou transmutação que é definida como a interpretação de um sistema de código para outro por meio de signos de sistemas não-verbais.

Segala (2010) propôs incluir a tradução intermodal como um quarto tipo de tradução aplicado às traduções que envolvem uma língua de sinais. Na verdade, a proposta capta a especificidade dos aspectos na tradução intralingual, tradução interlingual e intersemiótica que inclui uma língua de sinais. Ou seja, a tradução intermodal está imersa nesses três diferentes tipos de tradução identificados por Jakobson.

$\mathrm{Na}$ tradução de Língua Portuguesa para Libras, esses diferentes tipos de tradução precisam captar as especificidades envolvidas nesse processo, pois estamos diante de línguas em diferentes modalidades. Assim, vamos tratar essa tradução intermodal como um 
quarto tipo, conforme proposto por Segala (2010), mas salientamos que é uma tradução que envolve línguas, ou seja, sistemas verbais (tradução interlingual) e outros sistemas não-verbais (tradução intersemiótica). Importante esclarecer que a Libras, assim como outras línguas de sinais, configuram um sistema verbal, apesar de se apresentarem na modalidade visual-espacial.

Quadros, Souza e Segala (2013) apresentam o processo estabelecido nas traduções do português escrito para a Libras no contexto dos Cursos de Letras Libras. Os autores elencam, por exemplo, as seguintes estratégias: uso de explicitação, uso da soletração de palavras seguidos da introdução do termo em libras, uso de textos com glosas, gráficos e desenhos como intermediários entre o texto em português escrito e o texto final em Libras. Segala (2010) apresenta estas mesmas estratégias como frutos de diferentes modalidades de tradução, no sentido de Jakobson (1959). A tradução intralingual não será discutida aqui, pois estamos analisando os contextos de tradução no Curso de Letras Libras que envolvem duas línguas, portanto, uma tradução tipicamente interlingual. Trazemos na composição dessa tradução interlingual neste contexto específico, a tradução intersemiótica e a tradução intermodal como integrantes da tradução interlingual, não como coisas separadas, mas formas que adentram a mesma atividade de tradução. Estaremos dando ênfase à tradução intermodal, pois esta está diretamente relacionada com a especificidade das línguas de sinais.

\section{Tradução intermodal}

A tradução de um texto em Libras (língua visual-espacial) para um texto em português (língua oral-auditiva) ou vice-versa, envolve, é uma tradução interlingual permeada pela tradução intersemiótica e a tradução intermodal (SEGALA, 2010), mais especificamente, essa tradução que implica efeitos de modalidade (QUADROS, 2006).

A literatura existente, principalmente relativa a sistemas de tradução do inglês para a língua de sinais americana (ASL), converge 
para três pontos principais: a) a ideia de que os sistemas de tradução intermodal acompanham, em linhas gerais, os princípios, abordagens e técnicas já desenvolvidas para os sistemas intramodais (de uma língua oral-auditiva para outra língua oral-auditiva); b) a ideia de que os sistemas de tradução intermodal se subdividem, na verdade, em dois subsistemas: (1) o de tradução de uma língua oral-auditiva para um sistema de escrita da língua visual-espacial; e (2) o de síntese de sinais (visual-espacial) a partir desse sistema de escrita, que envolve a ideia de que a complexidade da tarefa está evidentemente relacionada ao sistema de escrita da língua visual-espacial adotado (SEGALA, 2010). Esses sistemas são apresentados como específicos porque envolvem duas línguas com modalidades diferentes: uma língua visual-espacial e outra língua oral-auditiva (ou na versão gráfica-visual).

Quadros e Souza (2008) fazem referência a este tipo de tradução quando analisam a relação entre as línguas na escrita e em sinais:

\begin{abstract}
A língua fonte (LF), portanto, é a língua Portuguesa escrita e a língua alvo (LA), é a língua brasileira de sinais na sua versão orall. Entende-se "oral" em como a língua na sua forma de expressão oral, no caso especifico das línguas de sinais, expressão em sinais. Como as modalidades das línguas envolvidas são diferentes, percebem-se efeitos de modalidade. (QUADROS \& SOUZA, 2008, p. 3).
\end{abstract}

As questões implicadas na tradução intermodal envolvem os seguintes aspectos:

a. O fato da Libras estar na versão "oral”, como apontado por Quadros e Souza (2008), ou seja, na versão em sinais que resulta na filmagem do texto em Libras, que vai determinar uma sobreposição de elementos da tradução e da interpretação, ou seja, os tradutores dispõem de tempo para realizar a tarefa da tradução do Português para a Libras, característica 
da atividade da tradução; mas no momento em que efetivamente realizam a filmagem da tradução, há características inerentes à atividade de interpretação, pois a Libras está na versão oral. A filmagem da versão em Libras apresenta-se com o corpo presente do tradutor que se expressa na Libras visualmente. A edição do texto em Libras acontece sobre a versão oral, exigindo a realização de novas filmagens (novas tomadas), porque é mais difícil editar um vídeo com um texto sendo produzido oralmente a editar um texto digitado por escrito. Essas são algumas características que se sobrepõem.

b. A questão da visibilidade do tradutor, uma vez que o tradutor produz o texto em Libras filmado, ou seja, o tradutor é visualizado e sua identidade é explícita (diferente de traduções envolvendo textos escritos, em que o tradutor pode torna-se, muitas vezes, invisível). No caso de textos em que a língua alvo é a Libras, os tradutores são necessariamente visíveis, atribuindo a eles a autoria da tradução. No contexto dos Cursos de Letras Libras, os tradutores filmavam a versão em Libras oral. Assim, as pessoas que assistiam ao texto em Libras, não tinham dúvida quanto a quem estava produzindo o texto, pois o corpo do tradutor estava presente e era visualizado diretamente pelos seus "leitores". Assim, a visibilidade desses tradutores estava garantida. Essa visibilidade também decorre da sobreposição das características inerentes à tradução e à interpretação. $\mathrm{O}$ fato dos tradutores se apresentarem fisicamente na versão em Libras interfere na relação de autoria do texto. No sentido reclamado pelos tradutores de textos escritos, isso é positivo, pois a autoria da tradução está visibilizada. No entanto, torna-se um problema para o autor do texto na língua de origem que torna-se invisível. O problema colocado nos Estudos da Tradução apresenta-se enquanto problema para o autor e não para o autor da tradução, neste caso. Isso se observa na interpretação simultânea, em que o intérprete pode ser reconhecido 
pelos seus receptores, embora de forma mais sutil, pois a voz pode não ser reconhecida, diferente do vídeo em Libras em que o corpo do tradutor está presente.

c. A necessidade do tradutor em "atuar" na produção em sinais (no sentido abordado por QUADROS; SOUZA, 2008), uma vez que o tradutor expõe o seu corpo diante da câmera e produz um texto em sinais que exigirá uma espécie de "performance" em sinais. Essa performance em sinais é organizada discursivamente usando recursos linguísticos (o texto em si na Libras) e paralinguísticos típicos de textos na modalidade visual-espacial (por exemplo, uso de descrições imagéticas, antropomorfismo, incorporação e uso do espaço de sinalização). A atuação a que nos referimos envolve a presença física do tradutor no momento da produção do texto em Libras. Essa presença diante das câmeras torna o ato em si uma performance, pois o tradutor produz o texto em Libras e assume diferentes papéis, entre o narrador que está apresentando o texto técnico-científico e, ao mesmo tempo, os papéis dos diferentes temas propostos por diferentes autores, por exemplo, que exigem o uso de recursos específicos das línguas visuais-espaciais que não necessariamente estejam presentes no texto original. A forma de apresentação de um texto em Libras inclui essas atividades performáticas. Por exemplo, na Língua Portuguesa escrita, a apresentação de itens acontece por meio de enumeração. O tradutor pega esta enumeração e apresenta-a utilizando o sistema de enumeração específico da Libras que exige a indicação dos itens elencados na mão (ver a figura 5 quando for discutido detalhes a respeito deste tipo de recurso espacial). Depois de indicar o item, normalmente, o mesmo é estabelecido em diferentes pontos espaciais que serão incorporados aos sinais e ao corpo do sinalizante, propriedade específica das línguas de sinais. Essa incorporação pode acontecer de diferentes formas, por exemplo, dando vida a um determinado aspecto 
para apresentar suas características, ou seja, o uso de antropomorfismo (SUTTON-SPENCE; NAPOLI, 2010), também pode simplesmente incorporar o elemento no próprio sinal, quando o sinal se realiza no espaço indicado para este item (QUADROS, 1997).

Essas questões devem fazer parte da formação dos tradutores e intérpretes de Libras e Português, uma vez que fazem parte da essência da atividade deste profissional. O fato da tradução de Português para a Libras envolver um misto de tradução (tempo de análise do texto original e tempo disponível para o planejamento da versão na língua alvo) e de interpretação (produção "oral” do texto alvo) têm implicações no texto traduzido. O texto alvo em sinais filmado não é de fácil edição, como um texto escrito. O vídeo apresenta uma produção "oral” que é filmada em Libras e envolve um processo de revisão bastante trabalhoso. Revisar o texto em Libras, editar e refazer a filmagem são características que não se aplicam a uma tradução envolvendo textos escritos. Assim, desenvolver estratégias de produção destas filmagens torna-se relevante. Os tradutores e os editores das filmagens devem trabalhar em parceria para a produção do material que inclui o texto em Libras.

A questão da visibilidade também é uma questão que deve ser levada em conta, pois um tradutor que está trabalhando em um texto escrito pode estar fazendo isso usando o seu pijama, mas o tradutor para a Libras, precisará se produzir e se apresentar adequadamente de acordo com o texto alvo. $\mathrm{O}$ tradutor de um texto em língua de sinais pode estar vestido como um dos personagens do texto, ou com roupas com cores sólidas e neutras ou, ainda, alternar cores de suas roupas de acordo com o que está sendo apresentado no texto final (informações semióticas que serão retomadas na sessão a seguir). A visibilidade envolve também o fato do tradutor ser identificado visualmente, ou seja, a autoria da tradução fica explicitada pela sua presença no vídeo. Isso tem tido consequências na tradução. A visibilidade do tradutor pode tornar o autor do texto invisível, problema oposto ao observado em traduções de textos 
escritos. Assim, cuidados na forma de apresentação da tradução, identificando claramente a autoria do texto original e a autoria da tradução são fundamentais. Isso tem sido feito por meio de uma apresentação inicial da referência do texto original pelo próprio tradutor associada a apresentação por escrito da referência, devidamente indicada pelo tradutor. Esses cuidados evitam ofuscar a autoria do texto original, mas também preservam a autoria da tradução. A questão da atuação do tradutor na hora da filmagem do texto em Libras é também alvo de atenção, pois enquanto efeito de modalidade exige a análise do processo tradutório em si. Isso tem também implicações de ordem subjetiva, pois os tradutores "aparecem" muito e isso tem um efeito psicológico do tipo do efeito observado em atores e atrizes de filmes, ou seja, os tradutores ficam "famosos" e a fama sobe pra cabeça (ABECHE; CANIATO; SANTOS, 2008). Alguns tradutores têm dificuldades de lidar com esse efeito de ordem subjetiva, o que não será discutido aqui, pois envolve outro campo de pesquisa.

$\mathrm{O}$ tradutor deve ter afinidade em atuar diante da câmera, ou seja, ele deve estar a vontade no ato tradutório incorporando personagens por meio de expressões faciais e movimentos corporais. Caso envolva obras literárias, os papéis do narrador e dos personagens são alternados por meio dos mecanismos de incorporação disponíveis na língua, como a incorporação facial de um personagem que o identifica. Se personagens de histórias infantis precisam ser antropomorfisados (dando a eles vida, no caso de animais ou objetos com características humanas), isso também vai passar pelo corpo do tradutor (SUTTON-SPENCE; NAPOLI, 2010). Nesse sentido nos referimos a essa tradução intermodal envolvendo atos performáticos. As descrições imagéticas, também referidas como classificadores, fazem parte das línguas de sinais. Campello (2013) trata das descrições imagéticas como algo mais amplo do que os classificadores, pois o termo classificadores é utilizado para referir o uso de morfemas que referem classes em algumas línguas (FERREIRA-BRITO, 1995). No entanto, nas línguas de sinais, essas descrições imagéticas estão mais intimamente relacionadas com 
uma "representação" visual do mundo, das coisas, das relações, dos conceitos (CAMPELLO, 2007, 2008). No caso específico da tradução, o tradutor de línguas de sinais precisa se apropriar dessas descrições imagéticas que apresentam representações icônicas do que está sendo dito e que parecem exigir também habilidades intrínsecas de um ator no ato da tradução produzida em vídeo para a Libras, como língua fonte. Aplicadas à tradução, Luchi (2014) apresenta o uso de descrições imagéticas como um componente que sobrepõe uma tradução interlingual (Português para a Libras) e uma tradução intersemiótica, por envolver representações visuais que não representam itens lexicais da Libras, mas formas de reprodução visual de partes do discurso em Libras que enriquecem o texto para além de uma linguística convencional. Parece que esses elementos visuais entram para a língua de sinais de uma forma tão produtiva que exigem uma revisão da separação entre os tipos de tradução interlingual e intersemiótica, assim como intermodal. Esses tipos de tradução se sobrepõem no texto em Libras, pois trazem elementos linguísticos combinados com elementos essencialmente visuais que apresentam também componentes linguísticos, no caso das descrições imagéticas, mas combinados com elementos não verbais, no sentido de não se enquadrarem na linguística convencional.

Portanto, a partir de agora estaremos abordando o entre lugares dos tipos de tradução, ou seja, as interfaces entre os tipos de tradução propostos por Jakobson e a tradução intermodal proposta por Segala, não mais como formas autônomas, mas sobrepostas. $\mathrm{Na}$ próxima seção, o foco será os cruzamentos entre a tradução intersemiótica e a tradução intermodal na tradução interlingual (Língua Portuguesa escrita para a Libras).

\subsection{Tradução intersemiótica: sobreposições entre os tipos de} tradução interlingual e intermodal

Para que se realize uma tradução intersemiótica - entre diferentes sistemas de signos - torna-se relevante observar as relações existentes entre os sentidos, os meios e as linguagens envolvidas 
no processo. A tradução de pensamentos em signos necessita de canais e linguagens que viabilizem socializar esses pensamentos, permitindo o intercâmbio de mensagens entre o homem e o mundo à sua volta. Cada sistema de signos constitui-se de acordo com sua especialidade característica, que possibilita sua articulação em conjunto com os órgãos emissores-receptores (sentidos humanos). Estes produzem as mensagens que reproduzem os sentidos. É pelos sentidos que os homens se comunicam entre si. Considerando isso, podemos vislumbrar as sobreposições entre a tradução intersemiótica e as traduções interlingual e intermodal. As línguas também envolvem os sentidos humanos com o propósito de comunicar. O fato das línguas de sinais usarem modalidade visual-espacial, com sentidos da visão e sinestésicos envolvidos, assim como as línguas faladas, serem orais-auditivas, envolvendo os sentidos da audição e, de certa forma, também sinestésicos, configura-se também formas de traduções intersemióticas nas duas línguas que se manifestam em duas modalidades (inter-lingual-modal). A tradução, portanto, envolve uma atividade altamente complexa implicada pelas línguas, pelas modalidades e pelos sentidos. A separação em tipos proposta por Jakobson e Segala apresenta um cunho metodológico, no sentido de organizar a análise da atividade de tradução, mas não significa sugerir atividades independentes conduzidas de formas diferentes.

Um dos campos mais promissores dos Estudos da Tradução é a tradução intersemiótica (VASCONCELLOS, 2008, p. 22). Jakobson (1959) define tradução intersemiótica como a transmutação de uma obra em um sistema de signos a outro, transferindo a forma e a tradução entre um sistema verbal e um não-verbal, como por exemplo, de um texto para ícones, desenhos, fotos, pintura, vídeo, cinema e outros. Diniz (1998) definiu tradução intersemiótica da seguinte forma:

A tradução intersemiótica, definida como tradução de um determinado sistema de signos para outro sistema semi- 
ótico, tem sua expressão entre sistemas os mais variados. Entre as traduções desse tipo, encontra-se a das artes plásticas e visuais para a linguagem verbal e vice-versa, assunto que tem sido estudado por muitos autores contemporâneos como Nelson Goodman, Michael Benton, Mario Praz, Júlio Plaza, Solange Oliveira e outros.

Atualmente, a tradução de uma língua oral e/ou escrita (inglês, português, francês, chinês, banto, guarani etc.) para a língua de sinais, pode-se ser feita por meio de filmagens ou utilizando-se a escrita de sinais que em si se apresenta como um sistema de escrita desenvolvido para escrever em língua de sinais que é composto por símbolos visuais para representar as configurações de mão, os movimentos, as expressões faciais e os movimentos do corpo das línguas de sinais, referido internacionalmente como signwriting (STUMP, 2005; SUTTON, 2014). A filmagem dos textos traduzidos para a Libras oral é a forma de registro mais usada entre os tradutores, uma vez que a tecnologia favorece os registros em vídeo e os surdos preferem assistir aos vídeos, embora o registro escrito seja uma alternativa que aos poucos começa a tomar forma. Por envolver uma filmagem, torna-se fundamental o uso da tradução intersemiótica, pois o vídeo apresenta a possibilidade de combinar o tradutor apresentando o texto em Libras e recursos semióticos com o objetivo de tornar o vídeo mais interessante, mais claro, mais eficiente, especialmente enquanto recurso didático. Segundo Krusser (2013), essas filmagens de textos em Libras precisam ser produzidas para uma leitura do texto em Libras que apresentem características pertinentes para ser legível e prazeiroza. O design pode contribuir neste sentido, pois pode associar imagens aos sinais para garantir a intelegibilidade e leiturabilidade dos textos em Libras. Observando as características específicas de cada texto, os textos alvos em Libras precisam incorporar informações semióticas que tornem o texto mais claro e interessante ao leitor. O tradutor estará, portanto, incorporando em sua tradução intermodal e interlinguística, a tradução intersemiótica. A seguir ilustra-se o uso dos 
recursos semióticos na tradução de um texto de material didático do IFSC (Krusser, 2013, p. 4):

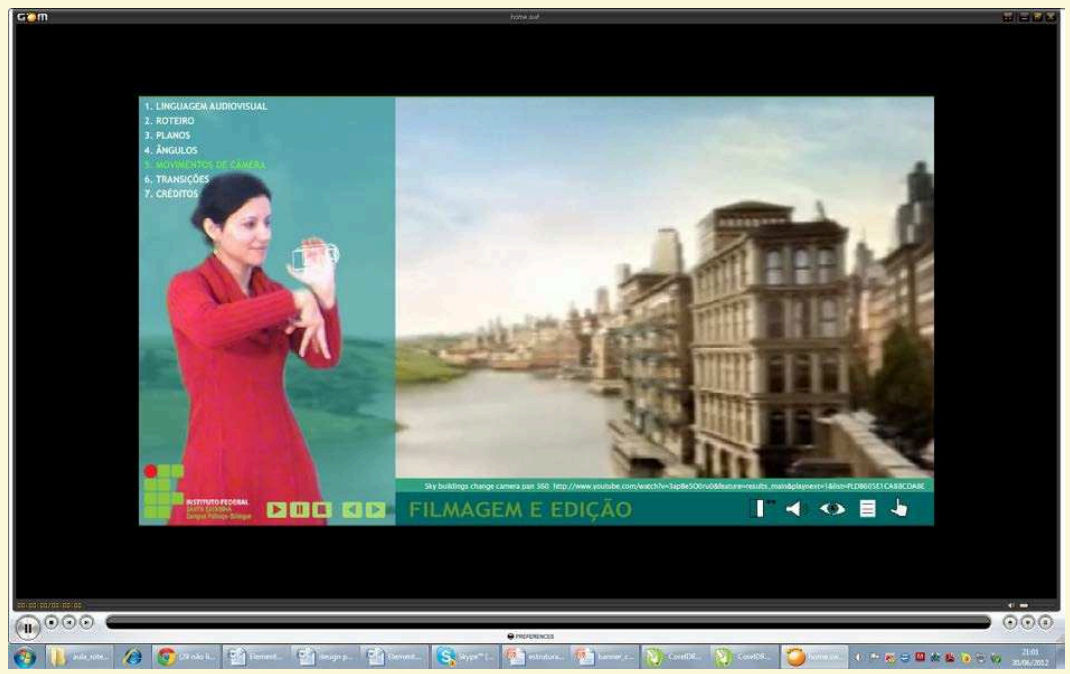

Figura 1: Página do layout selecionado para objeto de aprendizagem

Krusser (2013) apresenta o uso de recursos cinematográficos (PIMENTA, 2012), bem como o uso de legendas, comentários e ferramentas de manipulação de vídeo como recursos importantes para garantir a leiturabilidade dos textos traduzidos para a Libras. Outro exemplo do uso de recursos semióticos apresenta-se em um vídeo desenvolvido pelo Núcleo Multiprojetos de Tecnologia Educacional, da Universidade Federal de Santa Catarina (NUTE, http://nute.ufsc.br/site/ 2014) para um curso de formação de lideranças de prevenção às drogas (conselheiros6.nute.ufsc.br/libras/ vbook/index.php): 

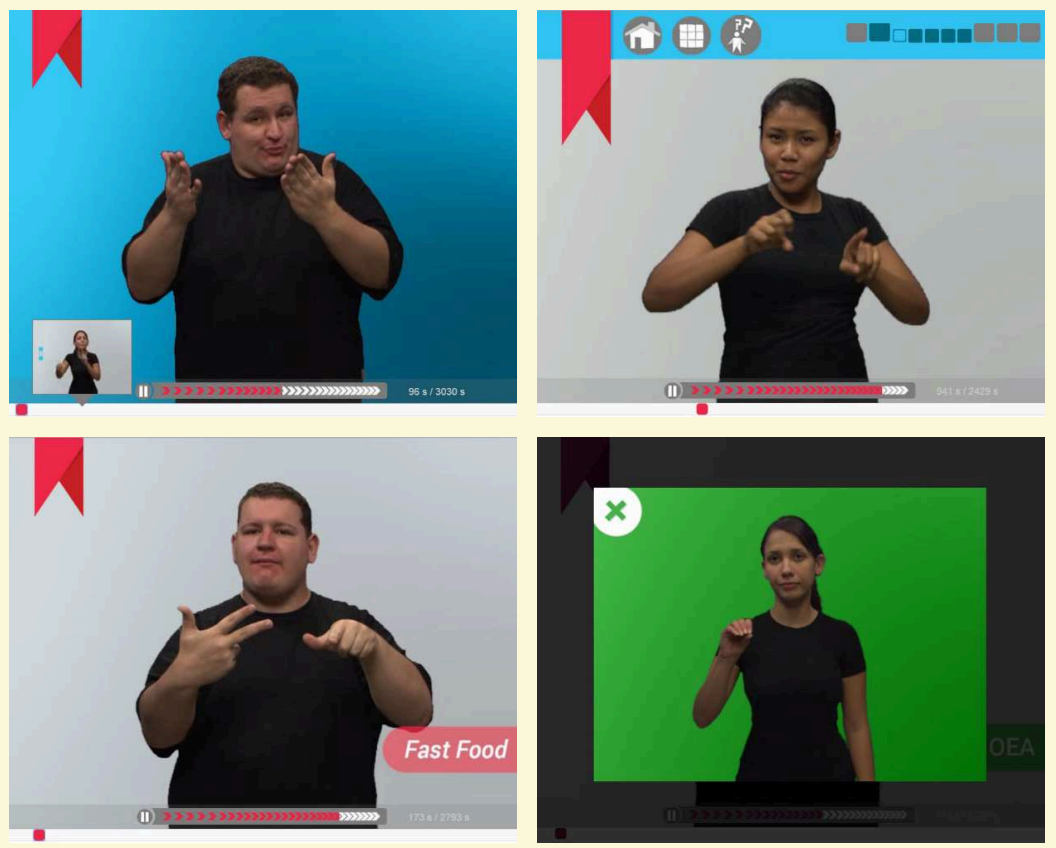

Figura 2: Imagens da interface do VBook (NUTE, 2014)

Esse V-Book incluiu a tradução para a Libras associada a informações que estão representadas no próprio layout da interface, o design dos ícones e a edição dos vídeos combinando todas essas linguagens. As ferramentas de manipulação dos vídeos em Libras também utilizam informações em Libras associadas com controlador de velocidade e de acompanhamento do vídeo. As cores são usadas com diferentes finalidades e completam o V-book determinando a leiturabilidade do texto em língua de sinais. Essa combinação envolve a tradução intersemiótica juntamente com a intermodal e a interlinguística.

Esse é um exemplo de tradução que sobrepõe a tradução interlingual (Português e Libras), a tradução intermodal (com vários elementos visuo-espaciais próprios da Libras, bem como descrições imagéticas) e a tradução intersemiótica (dentro da própria tra- 
dução, como na forma de apresentação do vídeo, incluindo ícones e imagens).

\subsection{Tradutor intermodal, intersemiótico e interlinguístico}

O tradutor intermodal, intersemiótico e interlinguístico, deve conhecer as duas línguas associadas às suas manifestações culturais e suas articulações em duas modalidades diferentes. $\mathrm{O}$ desconhecimento ou a falta de fluência pode comprometer as traduções e resultar na insatisfação dos leitores usuários da Libras.

Para realizar a tradução intermodal, intersemiótica e interlingual, a partir do português escrito, como língua-fonte, para Libras, língua-alvo, é necessário ter o perfil de um tradutor, usuário de Libras e Língua Portuguesa. Os tradutores surdos, nativos em Libras, tendo o português como L2, têm apresentado uma "norma surda" (STONE, 2009; SOUZA, 2010). O fato de tradutores surdos estarem imersos na língua e na cultura surda parece favorecer um tradução intercultural que vai ser marcada pela "norma surda" (STONE, 2009) que pode ser aprendida por tradutores ouvintes. Norma surda aqui está sendo usada no sentido apresentado por Stone (2009), também discutido por Souza (2010), ou seja, formas de processamento da informação que são acessadas pelos surdos por terem a língua de sinais como sua própria língua. Stone analisou traduções feitas por surdos e identificou que esse processamento é realizado várias vezes até se chegar na forma surda de apresentar o significado. O autor refere a norma surda como algo que os surdos se valem com maior propriedade para ensaiar e, então, chegar à língua alvo com sentidos que são mais apropriados aos próprios surdos. $\mathrm{Na}$ análise de dados comparando a atividade de tradução de tradutores ouvintes com tradutores surdos, Stone observou que os surdos criaram estratégias diferenciadas utilizando re-traduções sucessivas e esboços visuais (que podem ser considerados semióticos e multimodais para registrar informações própria da língua) até chegar no resultado final com um texto na língua de sinais mais apropriado em termos de senti- 
do para os leitores surdos, captando informações de ordem visual apresentadas espacialmente.

Com efeito, não basta ao tradutor conhecer as línguas implicadas na tradução. O tradutor precisa conhecer e saber as culturas que estão marcadas na língua de alguma forma apresentando sutilezas nas formas de traduzir sentidos. O tradutor deve ter a experiência na vida social, assim como apresentado por Russell (apud JAKOBSON, 1987, p. 428):

(...) as palavras, por si sós, são incapazes de transmitir significados que não tenham raízes em uma experiência direta e subjetiva do objeto do discurso. (JAKOBSON,1987, p. 428).

Por sua vez, Jakobson (1987) obtém desta argumentação uma conclusão fundamental "O significado de qualquer palavra ou frase é sempre um fato semiótico” (JACOBSON ,1987, p. 428).

Ser tradutor exige viver as línguas e quando se trata de uma língua na modalidade visual e espacial, o tradutor precisa ver os sentidos visualmente e espacialmente. Então, o tradutor intermodal, intersemiótico e interlinguístico deve ter boas raízes culturais e uma boa experiência na vida social em ambas as línguas, deve conhecer profundamente as várias nuances das duas culturas, para além do conhecimento das línguas.

Somando a isso, pretendemos considerar também a relevância da tradução para se construir espaços híbridos interculturais, pois, no caso desse curso, a língua brasileira de sinais é a língua de instrução, embora ainda os textos-fonte estejam na versão escrita da língua Portuguesa. (QUADROS; SOUZA, 2008, p. 1).

É preciso saber como se apresentar como ator, apresentador de TV, ter o espírito da arte, conhecer e utilizar a expressão cor- 
poral e incorporar os diferentes referentes de um texto produzido em Libras para câmera (filmadora), porque, na tradução de texto para Libras, a escrita está registrada no vídeo. Esse conhecimento performático se apresenta no texto em Libras, acessando a tradução interlinguística.

Os textos traduzidos para a língua brasileira de sinais são filmados, pois, é uma língua vista pelo outro, é uma língua que usa as mãos, o corpo, as expressões, é uma língua que depende da presença material do corpo do Dtradutor, por isso, também पator. (NOVAK, 2005, manuscrito).

Em suma, para traduzir os textos escritos na Língua Portuguesa para a Libras, o tradutor deve ter domínio das duas línguas; suas variações linguísticas, sociais e culturais, conhecimento semiótico, conhecimento das modalidades dessas línguas para, então, produzir um texto em Libras. A língua de chegada (Libras) deve ser clara e adequada aos leitores. Deve utilizar os sinais mais comuns aos surdos usuários de Libras, não seguindo a estrutura da Língua Portuguesa, evitando traduzir literalmente palavras por sinais, traduzindo sentidos, tendo em mente o leitor do texto em Libras.

\subsection{Tradução intermodal, intersemiótica e interlingual dos} materiais produzidos no Curso de Letras Libras da UFSC

O corpus analisado neste artigo foi retirado do material multimídia e alguns vídeos (trechos) do Curso de Letras Libras da modalidade à distância da UFSC, em que foram produzidos textos do português escrito - língua fonte - para a Libras - língua alvo. Toda a elaboração e execução do corpus analisado foram realizadas por uma equipe de tradutores de português e Libras. Foram selecionados trechos do material bilíngue disponível no Ambiente Virtual de Ensino de Aprendizagem, atualmente também disponível na Coleção do Letras Libras (www.libras.ufsc.br ). 
Por meio da análise dos vídeos (trechos) selecionados que contém os textos na língua alvo, foram observados os aspectos do processo de tradução empregados nesse tipo de modalidade tradutória.

No Curso Letras Libras, os tradutores partem dos textos escritos para a produção da tradução em vídeo na versão em língua de sinais. Esse processo tradutório é complemente novo, pois, envolve um texto escrito de uma língua falada no país e um texto oral na língua brasileira de sinais (QUADROS; SOUZA, 2008).

Essa equipe de trabalho foi formada a partir da criação do Curso de Letras Libras. Inicialmente, não se tinha a consciência de que os textos em língua de sinais resultantes das filmagens (como era considerado inicialmente) consistiam de textos traduzidos. A partir disso, a equipe de tradução do curso de letras libras passa a buscar soluções, considerando teorias e métodos dos Estudos da Tradução que poderiam ser implantados nas práticas tradutórias do português escrito para a língua brasileira de sinais (QUADROS; SOUZA, 2008).

Destarte, uma das demandas fortes que surgiram depois de consultas prévias aos tradutores/atores surdos foi a fidelidade na tradução. Em relação a isso, por diversas vezes, emergiu o histórico conflito tradutório de se traduzir palavra por palavra ou significado por significado (MUNDAY, 2001). Magalhães e Alves (2006) perceberam que esse tipo de problema surge entre tradutores novatos, o que estava acontecendo algumas vezes com a equipe de tradutores deste curso (QUADROS; SOUZA, 2008). As soluções encontradas pela equipe de trabalho foram baseadas em reflexões teórico-práticas juntamente com pesquisadores da área dos Estudos da Tradução (a exemplo, Maria Lúcia Vasconcellos, do Programa de Pós-Graduação em Estudos da Tradução, da Universidade Federal de Santa Catarina). Esse processo de reflexão viabilizou a revisão do status desse grupo de trabalho que passou a ser reconhecido como grupo de tradutores do Curso de Letras Libras. Ao se estabelecerem como tradutores, os textos passaram a ter outra dimensão e as práticas tradutórias passaram a se constituir de forma consistente (ver também histórico deste processo em Soares e Silva, 2014). Os tradutores eram surdos, no sentido de garantir a norma surda, 
mas ainda tornou-se necessário aprofundar questões envolvidas na tradução intermodal, intersemiótica na tradução interlingual.

Operacionalmente, a tradução da língua portuguesa (língua fonte) para Libras (língua alvo) foi realizada por meio de filmagens, que utilizava vídeo-captura das traduções sinalizadas dos textos em estúdio (sala de gravação dos vídeos com fundo próprio, refletores de luz, filmadora, televisão, computador, teleprompter).

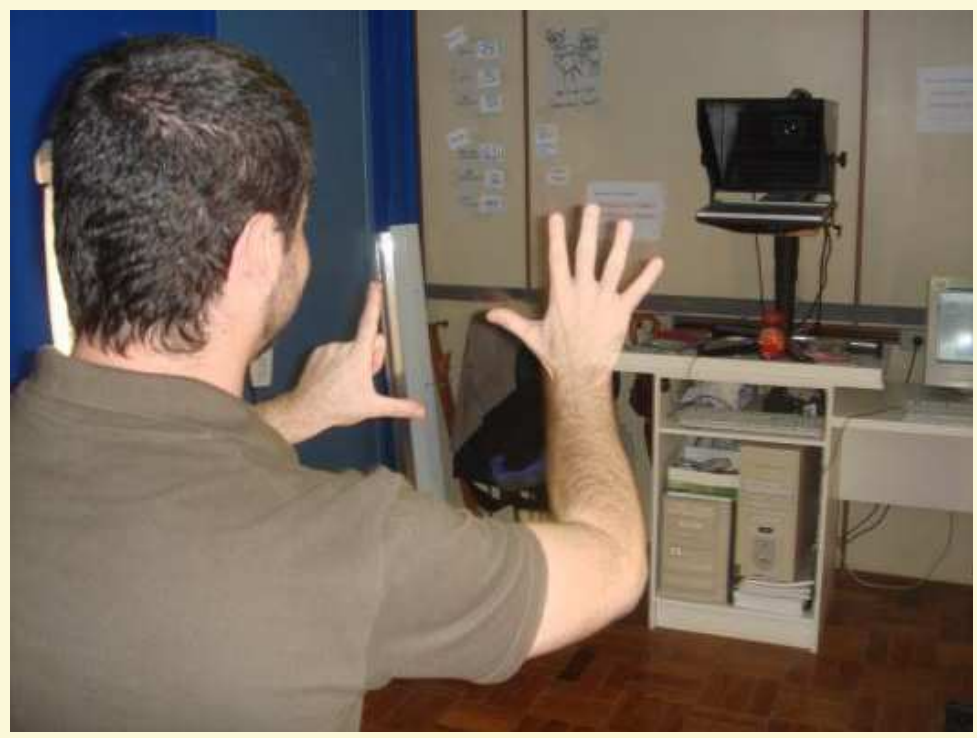

Figura 3: Estúdio de filmagem das traduções para a Libras

Em linhas gerais, a figura 3 ilustra o cenário que constituiu o ambiente de trabalho em que foram desenvolvidas as traduções em sinais dos conteúdos de ensino do Curso de Letras Libras (SEGALA, 2010; QUADROS; SOUZA, 2008).

Os procedimentos usados na tradução dos textos acadêmicos da Língua Portuguesa escrita para a Libras, envolveram várias etapas: (a) texto produzido em português pelo professor elaborador do 
conteúdo; (b) texto já redimensionado pelos designers instrucionais para apresentação no ambiente virtual de ensino, considerando a norma surda; (c) os tradutores procediam com leitura e análise dos termos do texto em português; (d) os tradutores elencavam as hipóteses e propostas de termos em Libras com o objetivo da tradução dos sentidos apresentados no texto fonte, sempre tendo em mente o leitor surdo; (e) os tradutores conversavam com os professores elaboradores do texto original sempre que necessário para esclarecimento dos sentidos e conceitos apresentados; (f) os tradutores procediam com a elaboração esquemas para servir de apoio à tradução (texto usando palavras/glosas do português incorporando elementos da Libras); (g) os tradutores realizavam a filmagem da versão em Libras; (h) os revisores procediam com a revisão das filmagens e apontavam os trechos que exigiriam refilmagem; (i) os tradutores procediam com a refilmagem dos trechos revisados; (j) os editores realizavam a edição do vídeo incorporando informações semióticas (imagens, legendas, ícones) indicadas pelos designers instrucionais (os agentes pedagógicos envolvidos na preparação dos materiais) e pelos próprios tradutores; (l) e então se encaminhava o vídeo em Libras para a publicação.

As filmagens eram realizadas em pequenos trechos para facilitar a refilmagem, caso fosse necessário. O tamanho do trecho era determinado pela complexidade envolvida no texto, mas normalmente envolvia em torno de 4 minutos.

Com relação aos dicionários, o tradutor usava, principalmente, o Houaiss, o Aurélio e o Michaelis. Na internet, ele buscava bons sites com informações confiáveis daquela área acadêmica. Com relação às pessoas envolvidas na produção dos materiais ou implicadas na área de atuação do texto produzido, o tradutor sempre poderia procurar seus pares e trocar informações sobre os significados e sinais possíveis para traduzi-lo.

Quando os tradutores se deparavam com termos em português que não apresentam um equivalente de sentido, ou seja, um sinal próprio, o tradutor discutia os termos com seus colegas tradutores e, quando necessário, eles criavam um novo sinal. O sinal criado 
passava a integrar o glossário dos termos usados no Curso de Letras Libras. O tradutor apresentava o sinal, seguido de uma explicação sobre o que seu significado e apresentava um exemplo contextualizado do novo termo. A próxima etapa envolvia a seleção das palavras nos vídeos em Libras para serem adicionados os links com a explicação desses termos no glossário, criando os hipertextos. O tradutor usava a paráfrase como procedimento para explicar os termos sem sinal próprio ou fazia uma transcrição de uma glosa, isto é, uma nota explicativa para cada termo selecionado. Esses procedimentos compreendiam em torno de 40 horas, ou seja, uma semana de trabalho para traduzir um texto de 12 páginas.

No momento em que o tradutor começava a fazer a filmagem da versão em Libras, ele não estava sozinho. Na frente dele, assistindo a tudo, ficava outro tradutor para identificar pequenas falhas e, se fosse o caso, refazer a filmagem, a fim de transmitir claramente o conteúdo do texto original, observando a norma surda. Esse segundo tradutor também auxilia na direção correta dos sinais quando imagens, ícones ou quaisquer outros elementos iriam coocorrer com o texto em Libras. Por exemplo, o sinal indicando um autor que estivesse legendado na parte do vídeo precisava ser indicado pelo tradutor da esquerda para a direita, na parte de baixo da tela, para ser encaixado visualmente de forma apropriada posteriormente, no momento da edição. Esses elementos visuais deveriam, portanto, já serem indicados antes da realização da tradução. As cenas eram filmadas uma a uma e, depois da edição, passava-se para o revisor. O revisor era uma pessoa nativa na Libras fluente nas duas línguas, assim ele tinha condições de perceber falhas e solicitar a revisão das cenas em que os textos não estivessem claros. Se ainda houvesse dúvidas quanto ao sinal a ser escolhido para traduzir um termo em português ou um sentido apresentado na versão em Libras, o tradutor poderia recorrer aos seus colegas tradutores para discutir e decidir a escolha em conjunto. Só depois desse processo é que uma tradução era posta à disposição no ambiente virtual de ensino aprendizado do Curso de Letras Libras, para ser transmitido para os polos do Brasil. 
Quanto às questões de ordem interlingual, intersemiótica e intermodal, os tradutores sempre levaram em consideração o texto a ser apresentado na Libras em vídeo. Isso significa que as informações precisavam estar articuladas de forma visual e apresentadas espacialmente de tal forma a garantir a compreensão das relações estabelecidas em cada texto. Por exemplo, as relações entre conceitos sempre eram apresentadas por meio de pontos espaciais que remetiam a visualização dos tipos de relação. Ao comparar conceitos, os tradutores estabeleciam os pontos nos espaços de forma contrastiva (como ilustrado na figura 4). Na figura 4, na primeira tomada, o sinal de LÍNGUA, o ponto fica esquerda e na segunda tomada o sinal de SOCIAL, fica na direita.
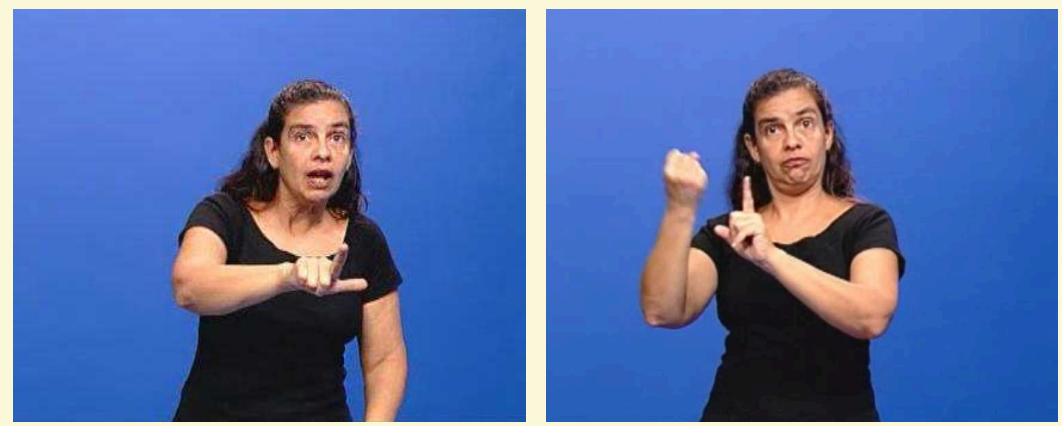

Figura 4: Comparação entre dois conceitos em Libras. Exemplo extraído da disciplina Sociolinguística do Curso de Letras Libras/2008

Caso precisassem elencar elementos em um texto, as bóias (termo usado por Liddell (2003), para referir sinais produzidos com a outra mão que persistem ao longo da produção na mão em que os sinais continuam a ser produzidos) eram usadas para apresentar de forma visual os elementos que estavam sendo referidos no texto de forma mais consistente. Na figura 5, uma das mãos foi usada para que os elementos fossem elencados e ficava "boiando" enquanto outros elementos eram introduzidos pela outra mão. 

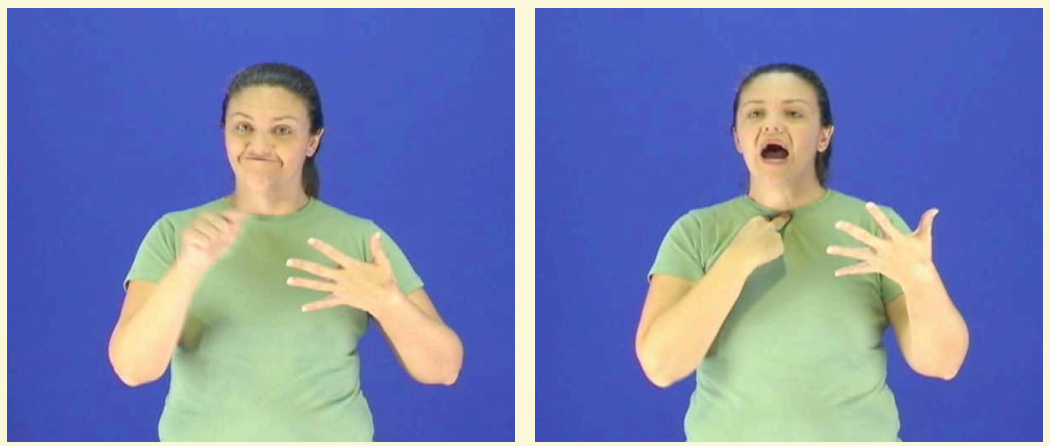

Figura 5: Uso de bóias na tradução para a Libras (neste exemplo: temos cinco elementos, o primeiro não poderá ser excluído). Exemplo extraído da disciplina de Aquisição da Linguagem do Curso de Letras Libras/2008

Outro tipo de relação espacial apresentada está relacionada com a noção de hierarquia, que na língua de sinais, também reflete as relações espaciais e os tipos de hierarquia de acordo com a disponibilização dos sinais no espaço (figura 6).
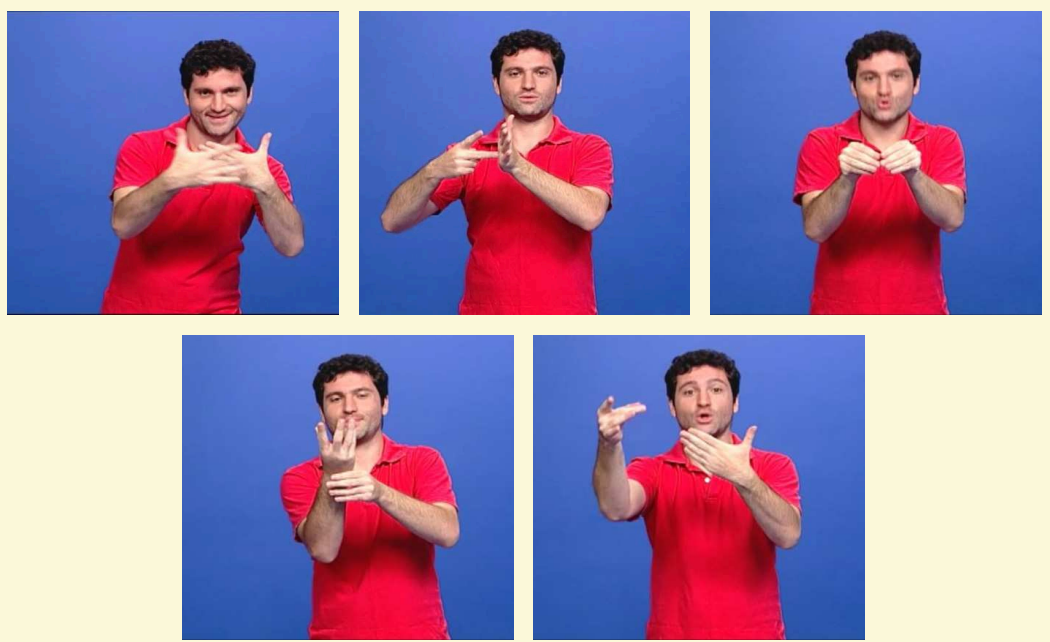

Figura 6: Relação hierarquizada entre os conceitos em Libras. Exemplo extraído da disciplina Semântica e Pragmática do Curso de Letras Libras/2008 
Na figura 6, o exemplo ilustra a relação de hierarquia estabelecida entre os sinais de SIGNIFICANTE e SIGNIFICADO com o sinal de SIGNO LINGUÍSTICO que é produzido no espaço acima dos dois primeiros introduzidos no espaço neutro a direita e a esquerda constituindo a relação hierárquica entre o conceito de signo linguístico que vai incluir os conceitos de significante e significado. Essa disponibilização espacial evidencia essa relação e pode ser mantida ao longo do discurso.

O uso do espaço também é usado para indicar diferentes referentes e conceitos que sejam tratados no discurso, por meio de uma espécie de enumeração ou de uma forma de elencar o que será tratado no texto (ver exemplo na figura 7).
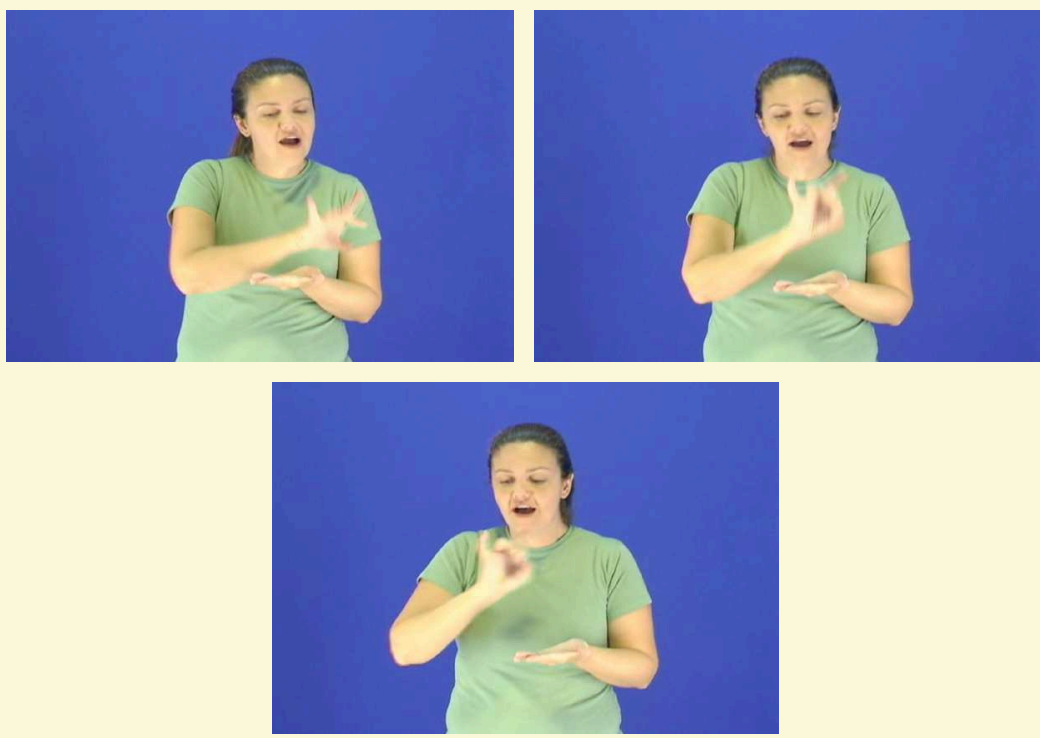

Figura 7: Referência a diferentes teorias em Libras usando o sinal CADA em diferentes pontos no espaço (neste exemplo: "estudar cada teoria" indicadas em três pontos espaciais diferentes por meio do sinal associado à direção do olhar). Exemplo extraído da disciplina de Aquisição da Linguagem do Curso de Letras Libras/2008 
Outro exemplo de tradução intermodal envolve a tradução de descritivos imagéticos (LUCHI, 2013), que foram discutidos anteriormente. Uma forma representada visualmente por meio de uma descrição imagética nos textos em línguas de sinais apela para representações que vão incluir formas que utilizam determinadas configurações de mão (por isso são restringidas por regras) associadas às formas reais representadas iconicamente por meio da expressão gestual (de forma aberta, ou seja, não compõem itens lexicais, pois tomam formas únicas diretamente motivadas pelos referentes). Nesse caso, temos uma tradução intermodal associada à tradução intersemiótica (ver exemplo nas figuras 8 e 9).

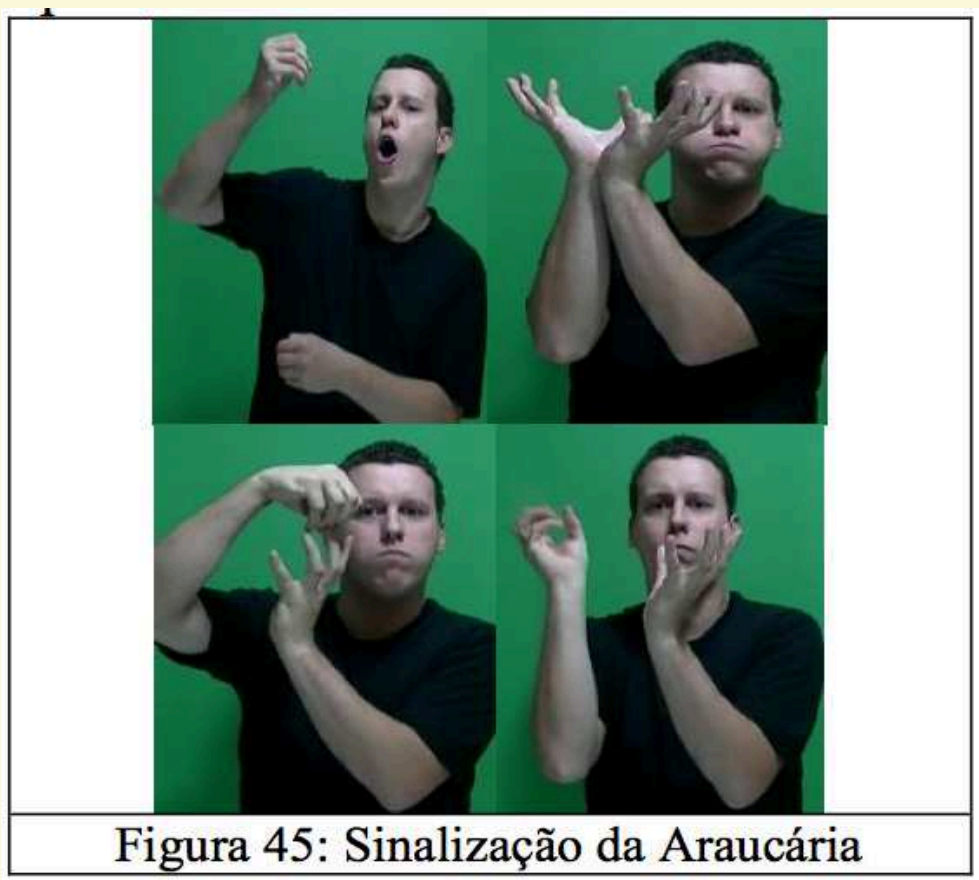

Figura 8: Figura da descrição imagética baseada em uma imagem de uma araucária (LUCHI, 2013:7) 

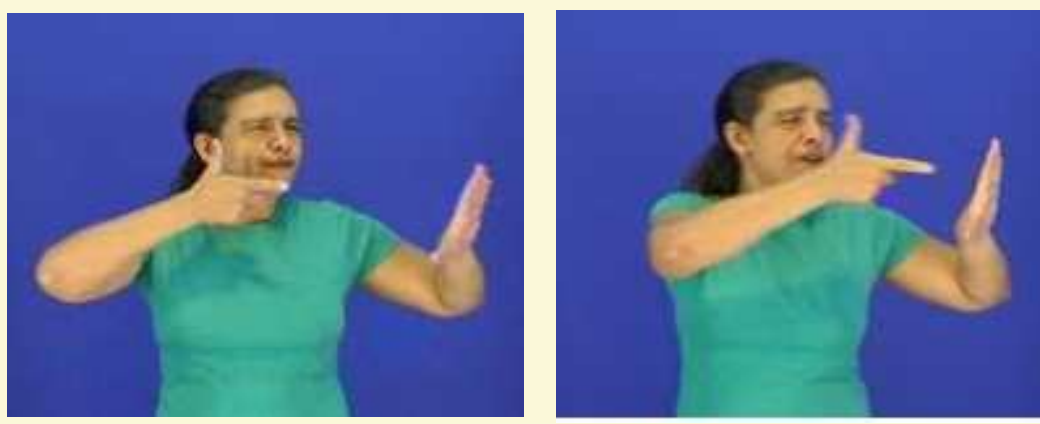

Figura 9: Figura da descrição imagética baseada em uma imagem (descrição de uma furadeira). Exemplo extraído da disciplina LIBRAS do Curso de Letras Libras $/ 2008$

Esses são exemplos de formas intermodais na tradução interlingual que são levadas em conta no momento da tradução de um texto escrito em Português para a Libras. São exemplos considerados interlinguais porque resultam da tradução do português para a Libras, com as características visuo-espaciais específicas das línguas de sinais, portanto, envolvem traduções intermodais. Essas características estão diretamente relacionadas com o uso do espaço nessas línguas.

Nesses exemplos, percebe-se que a tradução compõe a sobreposição de vários elementos que envolvem as modalidades das línguas, os elementos linguísticos, as questões culturais, os elementos semióticos e as quetões de ordem técnica. Os procedimentos de ordem técnica no uso das tecnologias para a implementação da tradução são importantes, pois viabilizam a produção final da tradução em Libras em vídeo. A tradução intermodal de português para Libras exige o uso de filmagens que implicam no uso de aparatos técnicos e conhecimento na área de produção de vídeo, associando a língua às informações de ordem interlinguística, intercultural e intersemiótica ao vídeo que resulta na tradução do texto em Libras. Essa composição é fundamental. A tradução, portanto, transcende as línguas e seu resultado inclui, necessariamente, uma grande complexidade de elementos. Entre eles, tratamos mais especifica- 
mente da tradução intermodal nas traduções interlinguais de textos do Português escrito para a Libras, que também incluem traduções intersemióticas.

\section{Conclusão}

A tradução intermodal representa uma tradução específica das línguas de sinais. Envolve componentes linguísticos e semióticos que vão integrar os sentidos produzidos em Libras a partir de textos escritos ou falados em português. Os tipos de tradução foram apresentados a partir de traduções de línguas orais-auditivas, normalmente, apresentadas na modalidade escrita, para a Libras. Ao traduzir textos para uma língua de sinais, em uma modalidade visual-espacial, passamos a integrar a tradução intermodal que capta especificidades dessa língua na tradução interlingual e na tradução intersemiótica, evidenciando os cruzamentos e sobreposições entre elas. Apresentamos algumas implicações operacionais que envolvem a tradução filmada em forma de vídeo e alguns aspectos de ordem linguística relacionados com o uso do espaço, ou seja, as informações de ordem visual-espacial que estão implicadas devido a modalidade das línguas de sinais. Dessa forma, a tradução intermodal é inerente à tradução de textos para a Libras.

Nota dos autores: Agradecemos as sugestões dadas pelos pareceristas anônimos deste artigo, pois contribuíram de forma consistente para a sua reelaboração. Agradecemos também aos tradutores dos Cursos de Letras Libras da Universidade Federal de Santa Catarina que participaram, mesmo que indiretamente, das análises reportadas neste artigo. 


\section{Referências}

ABECHE, Regina P. Christofolli; CAMIATO, Ângela e SANTOS, Lara Hauser. É hora do espetáculo da perversidade: o apriosionamento da subjetividade dentro dos realities shows. In Kátia Simone Ploner, Lísia Regina Ferreira Michels, Luciane Maria Schlindwein, Pedrinho A. Guareschi (Ed.) Ética e paradigmas sociais. Rio de Janeiro: Centro Edelstein de Pesquisas Sociais. 2008. 236-252.

BAHAN, B. Non-manual realization of agreement in American Sign Language. Ph.D. Dissertation, Boston University, Boston, MA. 1996.

BARAZZUTTI, Viviane. A desconstrução da oposição entre surdos e ouvintes a partir da (des)territorialização do intérprete de língua de sinais. 2011. Dissertação (Mestrado em Programa de PósGraduação em Tradução).

BARBOSA, Diego. Omissões na interpretação simultânea de conferência: língua portuguesa língua brasileira de sinais. Dissertação (Mestrado em Estudos da Tradução) Universidade Federal de Santa Catarina. 2014.

CAMPELLO, A. R. Pedagogia Visual / Sinal na Educação de Surdos. In: QUADROS, R. M.; PERLIN, G. (Org.) Estudos Surdos II. Petrópolis: Editora Arara Azul, 2007.

CAMPELlO, A. R. Pedagogia Visual na Educação dos Surdos. Tese Doutorado Universidade Federal de Santa Catarina. Florianópolis, 2008.

DINIZ, Thais Flores Nogueira. Tradução intersemiotica: do texto para a tela. Caderno de tradução, número 3. Florianópolis: UFSC, 1998.

FELÍCIO, Márcia. O surdo e a contação de histórias Análise da interpretação simultânea do conto. Dissertação (Mestrado em Estudos da Tradução) Universidade Federal de Santa Catarina. 2013.

FERREIRA-BRITO, L. Por uma gramática das línguas de sinais. Tempo Brasileiro. UFRJ. Rio de Janeiro. 1995. 
JAKOBSON, Roman. On Linguistic Aspects of Translation. In BROWER, R.A. (Ed.) - On Translation. Cambridge: Harvard University Press, 1959, p. 232-9.

LIDDELL, Scott. Grammar, Gesture, and Meaning in American Sign Language. Cambridge. University Cambridge Press. 2003.

LILLO-MARTIN, D. Where are all the modality effects? In Modality and Structure in Signed Language and Spoken Language. Richard P. Meier, Kearsy A. Cornier ans David G. Quinto (Ed.) Cambriedge: Cambriedge University Press. 2002.

LUCHI, M. Interpretação de descrições imageticas: Onde está o léxico? Dissertação de mestrado, programa de pós-graduação em estudos da tradução, Universidade Federal de Santa Catarina, Florianópolis. 2013.

NOVAK, P. A política do corpo. Texto apresentado no V Encontro de Performance do Instituto Hemisférico. Belo Horizonte. 2005.

PADDEN, C. Grammatical theory and signed languages. In Linguistics: The Cambridge Survey (Frederick J. Newmeyer, editor). New York: Cambridge University Press. 1988. p.250-265.

PIMENTA, N. A tradução de fábulas seguindo aspectos imagéticos da linguagem cinematográfica e da língua de sinais. Dissertação (Mestrado em Estudos da Tradução) Universidade Federal de Santa Catarina. 2012.

PFAU, R.; STEINBACH, M. and WOLL, B. (2012) Sign language: an international handbook. De Gruyter Mounton. Berlin and Boston.

QUADROS, Ronice Muller de . Efeitos de modalidade de línguas: as línguas de sinais. ETD : Educação Temática Digital, Campinas, v. 7, n.2, p. 167177, 2006.

QUADROS, Ronice Müller de. Contextualização dos estudos linguísticos sobre a libras no Brasil. In Estudos das Línguas de Sinais. Volume 1. Editora INSULAR. Florianópolis. 2013. 
QUADROS, Ronice Muller de ; SOUZA, Saulo Xavier ; SEGALA, Rimar Ramalho . Brazilian Sign Language Deaf Translation Performance: Descriptive Concepts and Approaches to Procedures Led by Deaf Translator Actors. Signed Language Interpreting in Brazil. 1ed.Washington, DC: Gallaudet University Press, 2012, v. 1, p. 3143.

QUADROS, Ronice Muller de ; AGUIAR, Silvana . O tradutor intérprete de língua de sinais: ontem, hoje e amanhã. Lengua de Senãs e Interpretación, v. 1, p. $91114,2010$.

QUADROS, Ronice Muller de ; SOUZA, Saulo Xavier. Aspectos da tradução/ encenação na língua de sinais brasileira para um ambiente virtual de ensino: práticas tradutórias do curso de letras libras. In: Ronice Müller de Quadros. (Org.). Estudos Surdos III. 1ed.Petropolis: Editora Arara Azul, 2008, v. III, p. 170209.

QUADROS, Ronice Muller de ; KARNOPP, Lodenir Becker. Estudos Linguísticos da Lingua de Sinais. Porto Alegre: Editora ArtMed. 2004.

QUADROS, Ronice Müller de. Políticas de fomento à pesquisa Línguas de Sinais. Seminário das Pós-Graduações em Letras, CAPES e UFSC. 2015. (manuscrito não-publicado).

SANTOS, Silvana Aguiar. A tradução/interpretação de língua de sinais no Brasil: uma análise das teses e dissertações de 1990 a 2010. Tese (Doutorado em Estudos da Tradução) Universidade Federal de Santa Catarina. 2013.

SEGALA, Rimar. Tradução intermodal e intersemiótica/interlinguística: português escrito para a língua de sinais. Dissertação (Mestrado em Estudos da Tradução) Universidade Federal de Santa Catarina. 2010.

SOARES, Janine Oliveira e SILVA, Rodrigo Custódio. Equipe de tradução do Curso de Letras Libras. Em QUADROS, Ronice Müller de. Letras Libras: ontem, hoje e amanhã. Editora da UFSC. 2014.

SOUZA, Saulo Xavier. Performances de tradução para a língua brasileira de sinais observadas no curso de letras libras. Dissertação (Mestrado em Programa de PósGraduação em Tradução) Universidade Federal de Santa Catarina. 2010. 
STOKOE, W. Sign and Culture: A Reader for Students of American Sign Language. Listok Press, Silver Spring, MD. 1960.

STONE, C. Toward a Deaf Translation Norm. Washington-DC, USA: Gallaudet University Press, 2009.

SUTTON-SPENCE, Rachel \& NAPOLI, Donna Jo. Anthropomorphism in sign languages: A look at poetry and storytelling with a focus on British Sign Language. Sign Language Studies, Volume 10:4, 442-475. 2010.

STUMPF, Marianne Rossi. Aprendizagem de Escrita de Língua de Sinais pelo sistema SignWrinting: Linguas de Sinais no papel e no computador. Porto Alegre: UFRGS, 2005.

SUTTON, Valerie. Lições sobre o SignWriting: Um Sistema de Escrita para Lingua de Sinais. Tradução e adaptação: STUMPF, Marianne, R.; COSTA, Antônio C. da Rocha. S/D. Disponível em http://www.librasgerais.com.br/materiais-inclusivos/ downloads/Licoes-de-SignWriting.pdf . Acesso em: 02 de outubro de 2015.

Recebido em: 20/06/2015

Aceito em: 30/09/2015 